\title{
BMJ Open Public, health professional and legislator perspectives on the concept of psychiatric disease: a population- based survey
}

\author{
Kari A O Tikkinen, ${ }^{\oplus 1}$ Jarno Rutanen, ${ }^{2}$ Allen Frances, ${ }^{3}$ Brea L Perry, ${ }^{4}$ \\ Brittany B Dennis, ${ }^{5,6}$ Arnav Agarwal, ${ }^{\oplus, 8}$ Amna Maqbool, ${ }^{9}$ Shanil Ebrahim, $, 8,10,11$ \\ Janne S Leinonen, ${ }^{12}$ Teppo L N Järvinen, ${ }^{13}$ Gordon H Guyatt ${ }^{8,14}$
}

To cite: Tikkinen $\mathrm{KAO}$, Rutanen J, Frances A, et al. Public, health professional and legislator perspectives on the concept of psychiatric disease: a populationbased survey. BMJ Open 2019;9:e024265. doi:10.1136/ bmjopen-2018-024265

- Prepublication history and additional material for this paper are available online. To view these files, please visit the journal online (http://dx.doi org/10.1136/bmjopen-2018024265).

Received 17 May 2018 Revised 13 January 2019 Accepted 12 February 2019

Check for updates

(C) Author(s) (or their employer(s)) 2019. Re-use permitted under CC BY-NC. No commercial re-use. See rights and permissions. Published by BMJ.

For numbered affiliations see end of article.

Correspondence to

Dr Kari A 0 Tikkinen

kari.tikkinen@gmail.com

\section{ABSTRACT}

Objective To assess which mental health-related states of being are perceived as diseases by psychiatrists, nonpsychiatric physicians, nurses, parliament members and laypeople.

Design and setting A population-based, mailed survey in Finland.

Participants Respondents from a random sample of 3000 laypeople, 1500 physicians, 1500 nurses and all 200 members of the parliament (MPs) of Finland.

Primary outcome measures Respondents' perspectives on 20 mental health-related states of being as diseases, measuring the extent of agreement with the claim: '[This state of being] is a disease'.

Results Of the 6200 people approached, we received 3259 eligible responses (53\%). Two conditions (schizophrenia and autism) were considered to be diseases by at least $75 \%$ and two states (grief and homosexuality) were considered not to be diseases by at least $75 \%$ in each group. A majority (at least 50\% in each group) considered seven states as diseases (anorexia, attention deficit hyperactivity disorder, bulimia, depression, generalised anxiety disorder, panic disorder and personality disorder) and three not to be diseases (absence of sexual desire, premature ejaculation and transsexualism). In six states, there was a wide divergence of opinion (alcoholism, drug addiction, gambling addiction, insomnia, social anxiety disorder and work exhaustion). Psychiatrists were significantly more inclined to considering states of being as diseases relative to other groups, followed by non-psychiatric physicians, nurses, MPs and laypeople.

Conclusions Respondents agreed that some conditions, such as schizophrenia and autism, are diseases and other states, such as grief and homosexuality, are not; for others, there was considerable disagreement. Psychiatrists are more inclined to consider mental health-related states of being as diseases compared with other physicians, who, in turn, are more inclined than other constituencies. Understanding notions of disease may underlie important debates in public policy and practice in areas of mental health and behaviour, and have implications for resource allocation and stigma.
Strengths and limitations of this study

- The survey assessed the concept of psychiatric disease over a substantial number-20 - of states potentially related to mental health.

- A large sample of physicians, nurses, laypeople and legislators responded to the survey.

- The survey achieved an acceptable response rate with a high level of completion among those who responded.

- The study sample proved similar in its characteristics to the target population in terms of numerous socioeconomic factors; the views of study participants are, therefore, likely to be representative of their particular stakeholder groups.

- We included only Finnish participants, and therefore, perceptions may differ in less affluent countries and those with different social and cultural values.

\section{INTRODUCTION}

Disease definitions in the context of psychiatry are ever-changing and subject to debate. ${ }^{12}$ Most recently, the Diagnostic and Statistical Manual of Mental Disorders, fifth edition (DSM-5), included contentious revisions that defined mental disorders as clinically significant behavioural or psychological syndromes that reflect underlying psychobiological dysfunction, but are not normative social or cultural responses to an external event or a result of social deviance. ${ }^{34}$ This complex definition reflects the dimensional properties of human emotion, cognition and behaviour, which might best be described as a continuum. This leads to disagreement about where to draw the line between normality and minority behaviours that may be aberrant, criminal and/or manifestations of mental illness. For instance, sadness, anxiety and despair may be normal responses to life's hardships, but can also be considered 
depressive or anxiety disorders and treated as medical problems. ${ }^{5}$ Homosexuality has been defined alternately as a sin, a criminal act, a disease and a normal variant of sexuality, depending on the cultural and historical context. $^{6}$

Mental disorders have been included or excluded from diagnostic manuals by historical accretion, reflecting the then-current views of the experts who develop the manuals. The popularity of psychoanalysis, the advent and increasing use of mental-health directed drugs, direct-to-consumer advertising and the growing number of mental health professionals have fuelled an increase in the number of conditions defined in the DSM and other diagnostic manuals, and thus, the number of people who are diagnosed. ${ }^{7-10}$ Contemporary epidemiological research suggests that as many as $25 \%$ of the population may qualify for a psychiatric diagnosis in a given year and $50 \%$ in a lifetime. ${ }^{11}$ These trends have prompted concern about medicalisation, or the growing tendency to define and treat normal processes and social problems as diseases, from both within and outside of psychiatry. ${ }^{4}$

In addition to reflecting evolving medical knowledge and practice, the concept of mental disorder is a social construction developed in the context of a particular cultural, historical and political environment. Definitions may also differ among lay and professional groups within a particular place and time, creating patterns that contribute to over-utilisation and under-utilisation of health services, including psychopharmaceutical intervention. Increasingly, the definition and labelling of mental disorder also have critical economic and juridical consequences for individuals and society. ${ }^{4} 12$

No previous study has compared perceptions of disease across professional groups (psychiatrists, other medical physicians and nurses), laypeople and legislators (laypeople who can influence health policy and the distribution of resources). We, therefore, in 2010, conducted the Finnish Disease (FIND) survey, ${ }^{13}$ which examined the views of these stakeholder groups to determine the extent to which they considered 60 states of being to be diseases. We have previously reported results for the entire set of 60 states of being included in the survey. ${ }^{13}$ Here, we focus, in detail, on 20 states that constitute possible mental disorders, explore differences in perceptions within and between different stakeholder groups, and look separately at responses from psychiatrists and other physicians.

\section{METHODS}

\section{The FIND survey study population}

We selected a random sample of 3000 laypeople, 1500 physicians, 1500 nurses and all 200 members of the parliament (MPs) of Finland. We identified laypeople aged between 18 and 75 years from the Finnish Population Register Centre, and physicians and nurses aged less than 65 years from the registries of Finnish Medical Association and Finnish Nurses Association. A previous publication presents more detailed study procedures,

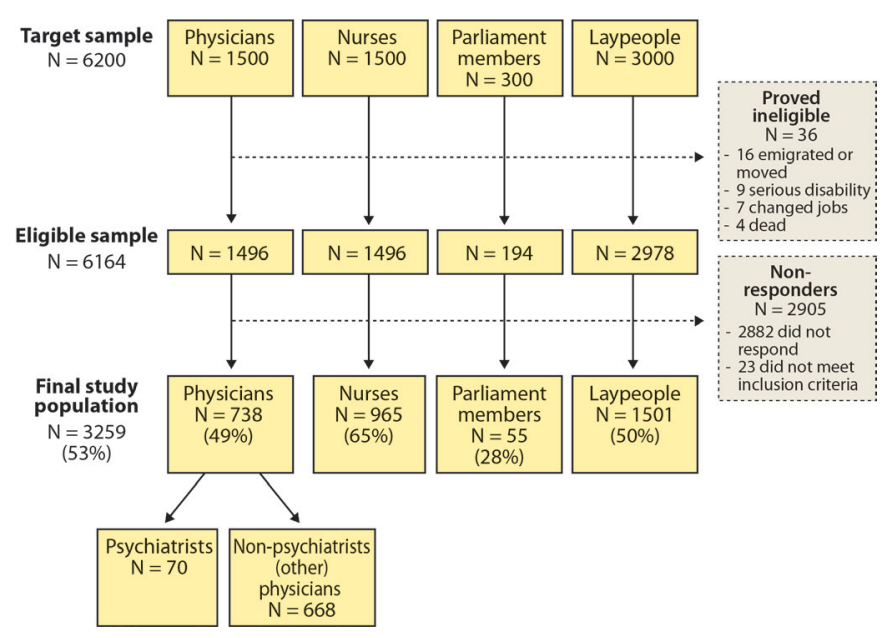

Figure 1 Study flowchart.

including randomisation of surveys (three different survey versions), assessing comprehension and exclusion criteria. ${ }^{13}$ The reporting of the study conforms to the Strengthening the Reporting of Observational Studies in Epidemiology statement. ${ }^{14}$

\section{Survey}

We selected 60 states of being that we considered to be familiar to the relevant stakeholders based on the existing literature, the International Classification of Diseases (ICD-10), and iterative discussion and consensus-building processes. ${ }^{13}$ We anticipated that some of these states would be considered as a disease by (almost) all, some by (almost) no one and that some states would elicit disagreement. We randomised the 60 states into three blocks (1, 2 and 3; each containing 20 states). We created three versions of the questionnaire: version A consisted of blocks in the order 1-2-3 (online supplementary material, pages 9-14), version B in the order 3-1-2 and version $C$ in the order 2-3-1. Within each sample group, we randomised respondents to one of the three versions (figure 1). We mailed the questionnaires in June 2010 (first response round) and sent reminders in August and October 2010 (second and third response round; questionnaires were resent to those who had not previously responded). We made precontacts with MPs by email and telephone. We asked participants to respond to a claim using a five-point Likert scale ranging from strongly disagree to strongly agree: '(This state of being) is a disease'.

For the present study (FIND psychiatry), we selected all 20 states related to mental health. Participants represented five respondent groups: psychiatrists, non-psychiatrist physicians, nurses, MPs and laypeople. The psychiatrists included those physicians who self-reported as being consultants or residents of adult psychiatry, paediatric psychiatry, adolescent psychiatry or forensic psychiatry. The non-psychiatrist (other) physician group included all other medical specialties (online supplementary material, pages 5-6). We excluded participants who did not demonstrate comprehension of the questionnaire $(n=23 \text { of eligible sample, } 0.4 \%)^{13}$ or who failed to 
respond to four or more mental health-related states of being ( $\mathrm{n}=21$ of eligible sample, $0.4 \%$ ) (figure 1 ).

\section{Statistical analysis}

We summarised results separately for each of the five groups (psychiatrists, non-psychiatrist physicians, nurses, MPs and laypeople). We calculated which states of being were considered to be a disease (Likert scale responses 4 and 5) by $\geq 75 \%$ or $\geq 50 \%$ of all respondent groups, and which states of being were not considered as a disease (Likert scale responses 1 and 2) by $\geq 75 \%$ or $\geq 50 \%$ of all respondent groups. The states of being not included in the previously mentioned categories were labelled as those with a large degree of variation.

We created a composite score using individuals' perceptions of each state of being. Responses ranged from ' 1 ' (strongly disagree that the state is a disease) to ' 5 ' (strongly agree that the state is a disease). As there were 20 states of being, the composite score had a potential range from 20 (participants reporting strongly disagree to all) to 100 (participants reporting strongly agree to all). For participants with missing responses between one to three states of being $(n=219,6.7 \%)$, data were imputed using the participants' average score of the completed responses. We performed sensitivity analysis by imputing 'neither agree nor disagree' to missing variables but results were similar and we do not report them here.

We constructed multivariable linear regression models using the composite score as the dependent variable and the following independent variables: (1) respondent group (ie, psychiatrists, non-psychiatric physicians, nurses, MPs and laypeople); (2) gender and (3) age. Because almost all nurses were female, gender, age and respondent group could not be included in a single model. Therefore, we constructed two models both of which included age (reflecting 10-year increments). The first model also included the respondent group and the second model included gender. All analyses were performed using STATA V.13. The estimated coefficients were reported with 95\% CIs and associated $p$ values and R-squared values.

\section{Patient involvement}

We did not involve patients when designing the study. We pilot tested the questionnaire with 20 laypeople and 5 physicians, and made minor revisions on the basis of the feedback. Laypeople (as well as all physicians and nurses) were sampled at random, and we did not collect information regarding a history of psychiatric illness.

\section{RESULTS}

Of the 6200 people approached, 6164 were deemed eligible, of whom 3280 (53.2\%) completed the questionnaire (figure 1). The study sample included: 70 psychiatrists, 668 non-psychiatrist physicians, 965 nurses, 55 MPs and 1501 laypeople. Among eligible respondents, the mean (SD) age was: psychiatrists 50.1 years (7.8), non-psychiatrist physicians 45.7 years (10.9), nurses 44.9 years (11.3), MPs 54.4 years (9.9) and laypeople 49.4 years (15.5). Among eligible respondents, the percentage women have across the five groups was as follows: psychiatrists $68.6 \%$, non-psychiatrist physicians $60.9 \%$, nurses $97.3 \%$, MPs $36.4 \%$ and laypeople $57.4 \%$. The online supplementary material, pages $3-4$, presents additional demographic data.

Of the 20 states of being, $\geq 75 \%$ of respondents from all groups considered two (schizophrenia and autism) to be diseases. More than $50 \%$ of participants from every group considered seven states to be diseases. Over $75 \%$ of respondents from all groups considered two states (grief and homosexuality) not to be diseases and over $50 \%$ in all groups considered three additional states not to be diseases. Six states met none of these criteria, and represent states for which there was large disagreement (figure 2 and box 1).

Overall, psychiatrists were most likely to consider states of being to be diseases followed by non-psychiatric physicians, nurses, MPs and laypeople (figure 2 and table 1). More specifically, the highest disease perception composite score was observed among psychiatrists (mean 73.5, SD 11.2), followed by non-psychiatrist physicians (mean 68.8, SD 10.9), nurses (mean 67.2, SD 11.4), MPs (mean 64.5, SD 10.2) and laypeople (mean 63.0, SD 12.9). We found the largest differences (in proportions of respondents considering states of being to be a disease; Likert scale responses 4 and 5) between groups in social anxiety disorder (difference between psychiatrists and laypeople 45.5), generalised anxiety disorder (difference 42.5), gambling addiction (difference 38.1) and drug addiction (difference 37.9 ).

In the multivariate linear regression, respondent group was significantly associated with disease perception composite score (table 1$)$. There was also a 0.37 decrease in the disease perception composite score $(95 \%$ CI -0.68 to $-0.05, \mathrm{p}=0.02$ ) per 10 -year incremental increase in age, indicating that older age was associated with less inclination to consider states to be diseases. In a separate multivariate linear regression, women were predicted to be more inclined to consider states of being as diseases (estimated gender difference in score $3.3,95 \%$ CI 2.36 to $4.21, \mathrm{p}<0.001)$. The impact of age was very similar in this second model.

\section{DISCUSSION}

\section{Statement of principal findings}

We identified mental health-related states of being that most respondents across all groups considered to be diseases (schizophrenia and autism), states that a majority considered to be diseases (depression, anorexia, panic disorder, generalised anxiety disorder, bulimia, attention deficit hyperactivity disorder and personality disorder), states that most respondents across all groups considered not to be diseases (grief and homosexuality), states that a majority of respondents considered not to be diseases 

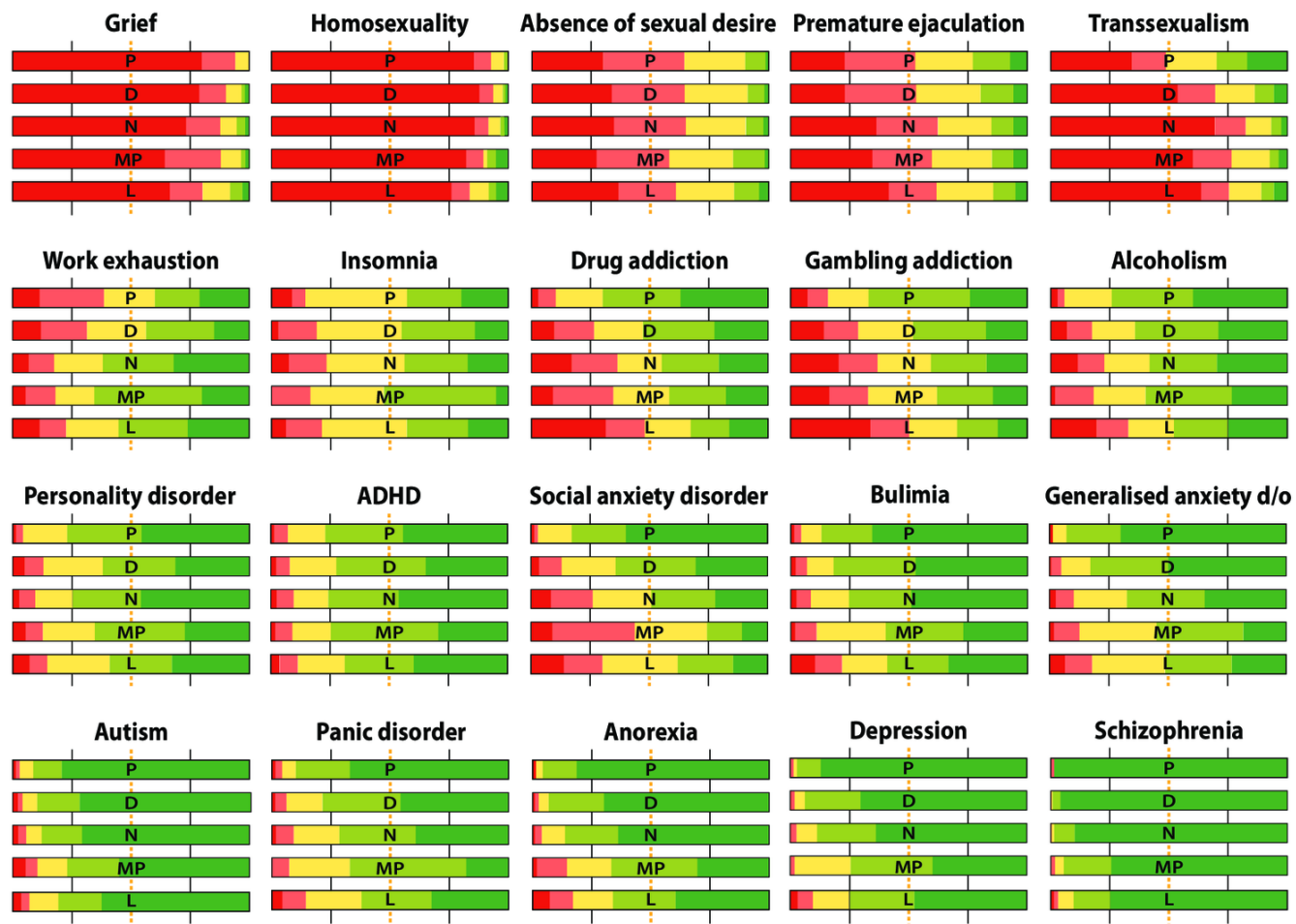

Figure 2 Proportions (divisions at $0.25,0.5$ and 0.75 ) to the claim 'this state of being is a disease' in psychiatrists (P), nonpsychiatrist physicians (D), nurses (N), parliament members (MP) and laypeople (L). Dark green represents individuals who strongly agree, light green those who agree to some extent, yellow those who neither agreed nor disagreed, light red those who disagree to some extent and dark red colour those who strongly disagree with the claim. d/o refers to disorder. ADHD, attention deficit hyperactivity disorder.

(absence of sexual desire, premature ejaculation and transsexualism) and states in which there was wide divergence in views (alcoholism, work exhaustion, insomnia, drug addiction, gambling addiction and social anxiety disorder) (box 1 and figure 2). Perceptions differed by group: the inclination to medicalise states of being was highest among psychiatrists and other medical professionals, and lowest among MPs and other laypeople, suggesting considerable divergence between professional and lay conceptions of disease. The magnitude of the difference between psychiatrists and laypeople was substantial: an average difference of more than 10 points on an 80-point scale of inclination to consider a state as a disease. The largest differences between the two groups were seen for social and generalised anxiety disorders and gambling and drug addictions, with psychiatrists being far more likely to define these states as diseases than laypeople. Finally, we found that that younger people and women were modestly more inclined to consider states to be diseases than older people and men were.

\section{Strengths and limitations of the study}

The strengths of our study include a large sample of physicians, nurses, laypeople and legislators, an acceptable response rate with a high level of completion among those who responded, and inclusion of a substantial number-20-of states potentially related to mental health. In addition, the sample proved similar in its characteristics to the target population in terms of age and gender distribution, education, employment and marital status. ${ }^{13}$ Moreover, we found no significant differences in perceptions or participant characteristics by response round, reducing concern regarding selection bias. ${ }^{13}$

One limitation of our study is that it included only Finnish participants, and therefore, perceptions may differ in less affluent countries and those with different social and cultural values. Western, democratic and high-income states are, however, likely to have a similar distribution of perceptions. ${ }^{15}$ Second, although we addressed the potential impact of wording in a pilot study, individuals may react differently to a particular question depending on how questions were worded ('framing effect'). ${ }^{13} 16-18$ Third, the response rate was substantially lower among legislators, raising issues of possible unrepresentativeness of those who did complete the survey. Finally, as this analysis is a part of larger scale FIND survey assessing not only mental health-related states of being but states from various other specialties, we did not survey whether these states were considered as 'mental health-related disorders' or 'psychiatric conditions' but as 'diseases'. Furthermore, we did not define word disease in the survey but relied on each respondent's own understandings of this term. These aspects can also be seen as limitations of our study.

\section{Comparison with other studies}

We used specific search criteria to search the Embase, Medline and PsycINFO databases (until 07 January 
Box 1 (A) States of being perceived as a disease

by $\geq 75 \%$ of respondents of all groups (psychiatrists, non-

psychiatrist physicians, nurses, members of parliament

and laypeople), (B) states of being perceived as a disease

by $\geq 50 \%$ but not $\geq 75 \%$ of respondents of all groups,

(C) states of being with large differences in perception

whether they are diseases or not, (D) states of being

perceived not as a disease by $\geq 50 \%$ but not $\geq 75 \%$ of

respondents of all groups and $(E)$ states of being perceived

as not a disease by $\geq 75 \%$ of respondents of all groups.

A. Perceived as a disease by $\geq 75 \%$ of respondents of all groups (response options 4 and 5)

Schizophrenia

Autism

B. Perceived as a disease by $\geq 50 \%$ of respondents of all groups, but not $\geq 75 \%$ of respondents of all groups (response options 4 and 5 )

Depression

Anorexia

Panic disorder

Generalised anxiety disorder

Bulimia

Attention deficit hyperactivity disorder

Personality disorder

C. Large differences in perceptions

Alcoholism

Work exhaustion

Insomnia

Drug addiction

Gambling addiction

Social anxiety disorder

D. Perceived not as a disease by $\geq 50 \%$ of respondents of all groups, but not $\geq 75 \%$ of respondents of all groups (response options 1 and 2)

Absence of sexual desire

Premature ejaculation

Transsexualism

E. Perceived not as a disease by $\geq 75 \%$ of respondents of all groups (response options 1 and 2)

Grief

Homosexuality

2019) to identify studies that assessed the concept of disease (online supplementary material, pages 7-8). Our search found as many as 14931 articles. Although we found many studies that examined (1) the public's and/ or professionals' attitudes toward people with mental illness, (2) the public's and/or professionals' attitudes about a single condition or (3) one stakeholder groups' attitudes toward a range of condition, we found only one study that assessed the concept of disease over a wide range of conditions across several stakeholder groups. This survey, conducted in the 1970s, examined 38 conditions among non-medical academics, medical academics, general practitioners and secondary school students, and included only three mental health-related conditions (alcoholism, depression and schizophrenia), all of which were included in our survey. ${ }^{19}$

In the prior study, $53 \%$ of secondary school students, $67 \%$ of non-medical academics, $61 \%$ of medical academics and $86 \%$ of general practitioners considered alcoholism to be a disease. These numbers are similar to our study, in which $48 \%$ of laypeople, $64 \%$ of non-psychiatric physicians and $74 \%$ of psychiatrists considered alcoholism to be a disease. Although almost all people considered schizophrenia to be a disease in our study (eg, 90\% of laypeople and $99 \%$ of both non-psychiatric physicians and psychiatrists), in the previous study, only $50 \%$ of secondary school students, $62 \%$ of non-medical academics, $77 \%$ of medical academics and $91 \%$ of general practitioners considered schizophrenia to be a disease. Differences in perceptions of depression proved even more striking: only $22 \%$ of secondary school students, $42 \%$ of non-medical academics, $50 \%$ of medical academics and $67 \%$ of general practitioners considered depression to be a disease in the earlier study, while in our research $75 \%$ of laypeople, $94 \%$ of non-psychiatric physicians and $97 \%$ of psychiatrists considered depression to be a disease.

Although these two studies were performed in different countries (the previous study in Canada and the UK, and our study in Finland), the most plausible explanation is that nowadays more people consider these mental-health related states of being as diseases than in the 1970s, and this is the case for both laypeople and healthcare providers. This pattern is consistent with the evidence of the widening definition of disease both within and beyond psychiatry, including the growing number of diagnoses in subsequent editions of the DSM and ICD, and the increasing number of people being diagnosed

Table 1 Multivariable linear regression for impact of respondent group and age on disease perception composite score

\begin{tabular}{|c|c|c|c|}
\hline Covariates & $\begin{array}{l}\text { Estimated coefficient (difference } \\
\text { on } 80 \text {-point scale) }\end{array}$ & $95 \% \mathrm{Cl}$ & $P$ value \\
\hline Age (per 10-year increment) & -0.37 & -0.68 to 0.05 & 0.02 \\
\hline \multicolumn{4}{|c|}{ Respondent group (all in comparison to laypeople) } \\
\hline Members of parliament & 1.71 & -1.53 to 4.94 & 0.30 \\
\hline Nurses & 4.12 & 3.14 to 5.10 & $<0.001$ \\
\hline Non-psychiatrist physicians & 5.70 & 4.60 to 6.80 & $<0.001$ \\
\hline Psychiatrists & 10.53 & 7.66 to 13.41 & $<0.001$ \\
\hline
\end{tabular}

${ }^{*}$ Per one unit increase in the covariates included in the model (eg, per 10-year increase in age), the estimated coefficient can be interpreted as the disease score change associated with the covariate. For instance, per 10-year increase in age (first covariate listed in the table), there is an average 0.37 decrease in disease score. 
Table 2 Implications of alternative viewpoints for states of being if accepted or rejected as diseases

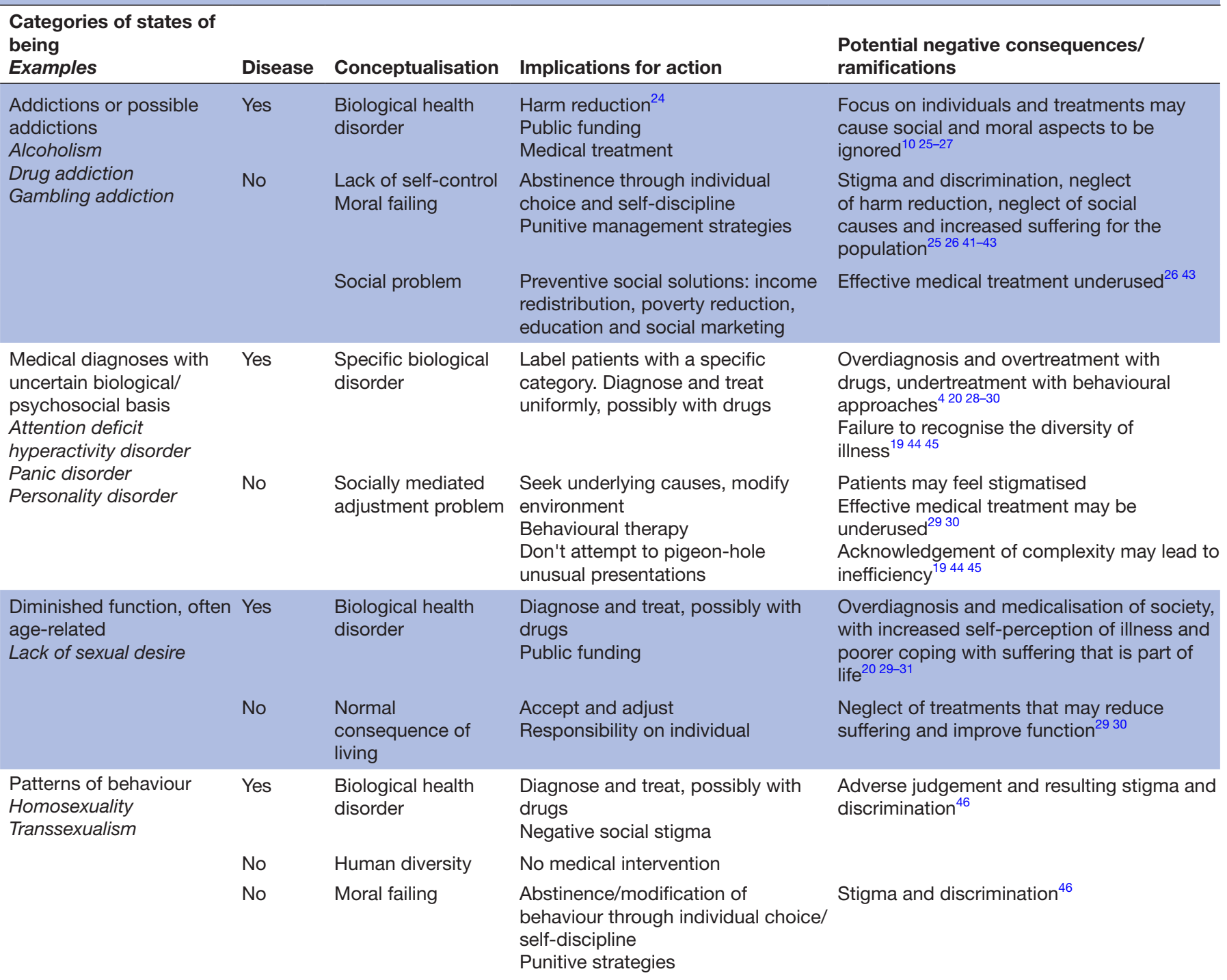

and treated for mild and subclinical psychiatric disorders. $^{40-23}$

\section{Meaning of the study: possible explanations and implications for clinicians and policymakers, and future research}

Table 2 categorises states of being potentially related to mental health (addiction, diagnoses with uncertain biological basis, diminished function and behaviour patterns), revealing commonalities that may lead to characterisation as disease or non-disease, implications for action and consequences. These considerations highlight the importance of the issue of categorisation of disease and non-disease.

Whether one conceives a state of being as a diseaseone might call this medicalisation-or not has important implications. On one hand, medicalisation increases public awareness of mental illness and is likely to increase the social acceptability of suffering from mental illness, may increase public funding devoted to the management of mental problems and to research addressing those problems, may increase rates of help-seeking for mental health problems and may facilitate access to care (eg, insurance reimbursement). These consequences of medicalisation have undoubtedly contributed to improvements in quality of life for many people.

In addition, medicalisation may lead to a more compassionate and less judgmental view of the afflicted, and influence views on how best to help people with their problems. For instance, Canada has recently witnessed a debate regarding harm reduction and safe injection sites as a way of dealing with drug addiction. ${ }^{24}$ Those inclined to view drug addiction as a disease have tended to support these strategies. Those who view addiction as a moral failure have been included to oppose these management approaches.

On the other hand, medicalisation generally promotes the minimisation of social and cultural explanations for human suffering (eg, social inequality). ${ }^{1025-27}$ Medicalisation is likely to lead to pharmacological interventions, even when psychotherapeutic treatment or lifestyle modifications (eg, regular exercise) or even reassurance are 
equally or more effective. ${ }^{42028-30}$ For example, physicians who consider social anxiety disorder to be a disease (over $80 \%$ of psychiatrists and two-thirds of other physicians-figure 2) may be more prone to offer medical treatment; those who do not may normalise the experience and offer reassurance (perhaps in keeping with their patients' views-less than $40 \%$ were inclined to the disease label). Thus, general practitioners holding medicalised conceptions of mental health conditions may be driving increasing diagnosis and treatment of mental illness by clinicians with limited formal training in psychiatry, contributing to overutilisation of psychotropic medications. ${ }^{4} 2028-30$

Similarly, labelling work exhaustion as a disease may lead clinicians to focus on the individual and not to work-related factors, such as bullying, management problems and work overload. In this kind of situations, the problem is again not only potential overuse of pharmacological interventions but also underuse of interventions that could lead to better outcomes, such as occupational rehabilitation. ${ }^{4029-31}$ Finally, with healthcare consuming an ever-increasing proportion of the gross domestic product of developed countries, medicalisation may target resources toward increasingly minor conditions and away from other threats to population health. ${ }^{32}$

An important contribution of this study is our finding regarding the gradient of medicalisation across groups, and particularly, the much greater inclination for psychiatrists to label states of being as diseases. For some states (eg, approximately two-thirds of psychiatrists see drug and gambling addictions as diseases; this is true of only one-third of laypeople-figure 2), one might view this as an enlightened view by psychiatrists associated with a reluctance to blame the victim, and a desire to provide help rather than censure. For other states, in which there is a large discrepancy (social anxiety and generalised anxiety disorder), one might see the nefarious influence of the pharmaceutical industry and specialty self-interest leading to over-medicalisation resulting in approaches that do more harm than good. ${ }^{2133}$

The view of the psychiatrists who participated in our study is reflected in the expansion of disease definitions that took place in the new edition of the diagnostic manual, DSM-5, which has raised criticism of overdiagnosis and treatment in the field of psychiatry. ${ }^{34-36}$ Other observers have suggested that the revised DSM is a work in progress that serves as a better platform for developing neuroscience and brings psychiatry closer to rest of the medicine. ${ }^{3738}$ The contrasting views of professionals and laypeople provide a possible justification for lay input into medical practice, including lay participation in clinical practice guidelines and diagnostic manuals. ${ }^{39}$

Our results, therefore, highlight the desirability of a more inclusive conversation regarding what states of being should be considered diseases, and the implications of these decisions, particularly, around issues of medicalisation. Our findings reflect on the profound implications of attitudes regarding which health states should be seen as diseases; one could argue that this paper should be required reading for those categorising health states, and making recommendations regarding their management, both in the clinical and health policy spheres.

Laypeople are now routinely included in clinical practice guideline panels. ${ }^{40}$ Including them in groups that produce diagnostic manuals would also be highly desirable. In terms of future research, qualitative studies exploring the reasons for peoples' decisions regarding what states constitute diseases, and the implications they see for these decisions would likely provide additional important insights into this crucial issue.

\section{Author affiliations}

${ }^{1}$ Departments of Urology and Public Health, Helsinki University Hospital and University of Helsinki, Helsinki, Finland

${ }^{2}$ Department of Internal Medicine, Centre for Rheumatic Diseases, Tampere University Hospital, Tampere, Finland

${ }^{3}$ Department of Psychiatry, Duke University, Durham, North Carolina, USA

${ }^{4}$ Department of Sociology, Indiana University Network Science Institute, Indiana University, Bloomington, Indiana, USA

${ }^{5}$ Department of Medicine, St George's University of London, London, UK

${ }^{6}$ Peter Boris Centre for Addictions Research, St. Joseph's Healthcare Hamilton, Hamilton, Ontario, Canada

${ }^{7}$ Department of Medicine, University of Toronto, Toronto, Ontario, Canada

${ }^{8}$ Department of Health Research Methods, Evidence, and Impact, McMaster University, Hamilton, Ontario, Canada

${ }^{9}$ Faculty of Dentistry, Schulich School of Medicine \& Dentistry, Western University, London, Ontario, Canada

${ }^{10}$ Systematic Overviews Through Advancing Research Technology (SORT), Child Health Evaluative Sciences, The Hospital for Sick Children, Toronto, Ontario, Canada

${ }^{11}$ Meta-Research Innovation Center at Stanford (METRICS), Stanford University, Stanford, California, USA

${ }^{12}$ Services for Citizens Division, State Treasury, Helsinki, Finland

${ }^{13}$ Department of Orthopaedics and Traumatology, University of Helsinki, Helsinki, Finland

${ }^{14}$ Department of Medicine, McMaster University, Hamilton, Ontario, Canada

Acknowledgements The authors thank Samantha Craigie for assisting in the literature review.

Contributors KAOT, JSL and TLNJ conceptualised the study. KAOT and TLNJ obtained funding. KAOT collected the data. KAOT, JR, AA, AM, SE, JSL and TLNJ participated in the literature review. KAOT, BBD, AA and GHG developed the analysis plan. KAOT, BBD, AA and GHG analysed the data. All the authors contributed to the interpretation of the results. KAOT, JR, AF, BLP, AM and GHG drafted the manuscript. All the authors contributed to the revision, and approved the final version of the manuscript. KAOT is the guarantor.

Funding This study was supported by the Competitive Research Funding of the Pirkanmaa Hospital District (grants 9L033 and 9K043), the Academy of Finland (grants 276046 and 309387), the Competitive Research Funding of the Helsinki and Uusimaa Hospital District (grants TYH2016135, TYH2017114, TYH2018120 and TYH2019321), the Jane and Aatos Erkko Foundation, and the Sigrid Jusélius Foundation.

Disclaimer The funding sources had no role in design and conduct of the study; collection, management, analysis and interpretation of the data; and preparation, review or approval of the manuscript. The authors' work was independent of the funders.

Competing interests JSL practices insurance medicine and is the chief medical officer at Services for Citizens Division, State Treasury, Finland. SE is employed by Deloitte LLP. KAOT, JR, AF, BLP, BBD, AA, AM, TLNJ and GHG declare no conflicts of interest.

Patient consent for publication Not required.

Ethics approval In accordance with the Finnish regulations on questionnaire surveys, the ethics committee of the Pirkanmaa Hospital District in Finland granted exemption from ethical review (R11110). 
Provenance and peer review Not commissioned; externally peer reviewed.

Data sharing statement The raw data of the FIND Survey are available at the Dryad Digital Repository (datadryad.org) (https://datadryad.org/resource/doi:10. 5061/dryad.94qh5).

Open access This is an open access article distributed in accordance with the Creative Commons Attribution Non Commercial (CC BY-NC 4.0) license, which permits others to distribute, remix, adapt, build upon this work non-commercially, and license their derivative works on different terms, provided the original work is properly cited, appropriate credit is given, any changes made indicated, and the use is non-commercial. See: http://creativecommons.org/licenses/by-nc/4.0/.

\section{REFERENCES}

1. ICD-10: World Health Organization. The ICD-10 classification of mental and behavioural disorders: clinical descriptions and diagnostic guidelines. 1: World Health Organization, 1992.

2. DSM: American Psychiatric Association. Diagnostic and statistical manual of mental disorders (DSM-5®): American Psychiatric Pub, 2013.

3. Thyer BA. "The DSM-5 definition of mental disorder: critique and alternatives.". In: Critical Thinking in Clinical Assessment and Diagnosis: Springer International Publishing, 2015:45-68.

4. Frances A. Saving Normal. New York: Harper Collins, 2013.

5. Wakefield JC, First MB. Clarifying the boundary between normality and disorder: a fundamental conceptual challenge for psychiatry. Can J Psychiatry 2013;58:603-5.

6. Conrad P, Schneider JW. Deviance and medicalization: from baldness to sickness: Temple University Press, 2010.

7. Blumenthal-Barby JS. Psychiatry's new manual (DSM-5): ethical and conceptual dimensions. J Med Ethics 2014;40:531-6.

8. Frances A. The first draft of DSM-V. BMJ 2010;340:c1168.

9. Wakefield JC. DSM-5, psychiatric epidemiology and the false positives problem. Epidemiol Psychiatr Sci 2015;24:188-96.

10. Conrad $P$. The medicalization of society: on the transformation of human conditions into treatable disorders. Hopkins Fulfillment Service 2007

11. Kessler RC, Berglund P, Demler O, et al. Lifetime prevalence and age-of-onset distributions of DSM-IV disorders in the National Comorbidity Survey Replication. Arch Gen Psychiatry 2005;62:593-602.

12. Temple LK, McLeod RS, Gallinger S, et al. Essays on science and society. Defining disease in the genomics era. Science 2001;293:807-8.

13. Tikkinen KA, Leinonen JS, Guyatt $\mathrm{GH}$, et al. What is a disease? Perspectives of the public, health professionals and legislators. BMJ Open 2012;2:e001632.

14. von Elm E, Altman DG, Egger M, et al. Strengthening the Reporting of Observational Studies in Epidemiology (STROBE) statement: guidelines for reporting observational studies. BMJ 2007;335:806-8.

15. Pescosolido BA, Medina TR, Martin JK, et al. The "backbone" of stigma: identifying the global core of public prejudice associated with mental illness. Am J Public Health 2013;103:853-60.

16. Gallagher KM, Updegraff JA. Health message framing effects on attitudes, intentions, and behavior: a meta-analytic review. Ann Behav Med 2012;43:101-16.

17. Tversky A, Kahneman D. The framing of decisions and the psychology of choice. Science 1981;211:453-8.

18. Akl EA, Oxman AD, Herrin J, et al. Framing of health information messages. Cochrane Database Syst Rev 2011:CD006777.
19. Campbell EJ, Scadding JG, Roberts RS. The concept of disease. $\mathrm{Br}$ Med J 1979;2:757-62.

20. Moynihan R, Heath I, Henry D. Selling sickness: the pharmaceutical industry and disease mongering. BMJ 2002;324:886-91.

21. Moynihan RN, Cooke GP, Doust JA, et al. Expanding disease definitions in guidelines and expert panel ties to industry: a crosssectional study of common conditions in the United States. PLoS Med 2013;10:e1001500.

22. Pathirana T, Clark J, Moynihan R. Mapping the drivers of overdiagnosis to potential solutions. BMJ 2017;358:j3879.

23. Doust J, Vandvik PO, Qaseem A, et al. Guidance for modifying the definition of diseases: a checklist. JAMA Intern Med 2017;177:1020-5.

24. Small D. Canada's highest court unchains injection drug users; implications for harm reduction as standard of healthcare. Harm Reduct J 2012;9:34.

25. Levy N. The social: a missing term in the debate over addiction and voluntary control. Am J Bioeth 2007;7:35-6.

26. Madueme $\mathrm{H}$. Addiction as an amoral condition? The case remains unproven. Am J Bioeth 2007;7:25-7.

27. Moscrop A. Medicalisation, morality, and addiction: why we should be wary of problem gamblers in primary care. $\mathrm{Br} J$ Gen Pract 2011;61:e836-8.

28. Abraham J. Pharmaceuticalization of society in context: theoretical, empirical and health dimensions. Sociology 2010;44:603-22.

29. Metzl JM, Herzig RM. Medicalisation in the 21st century: introduction. Lancet 2007;369:697-8.

30. Smith R. In search of "non-disease". BMJ 2002;324:883-5.

31. Culture KA. bereavement, and psychiatry. Lancet 2012;379:608-9.

32. Conrad P, Mackie T, Mehrotra A. Estimating the costs of medicalization. Soc Sci Med 2010;70:1943-7.

33. Whitaker R, Cosgrove L. Corruption impairs discussion on long term use of psychiatric drugs. BMJ 2015;350:h2953.

34. First MB, Wakefield JC. Diagnostic criteria as dysfunction indicators: bridging the chasm between the definition of mental disorder and diagnostic criteria for specific disorders. Can J Psychiatry 2013;58:663-9.

35. Frances A. The past, present and future of psychiatric diagnosis. World Psychiatry 2013;12:111-2.

36. Friedman RA. Grief, depression, and the DSM-5. N Engl J Med 2012;366:1855-7.

37. Kupfer DJ, Kuhl EA, Regier DA. DSM-5--the future arrived. JAMA 2013;309:1691-2.

38. Kupfer DJ, Regier DA. Neuroscience, clinical evidence, and the future of psychiatric classification in DSM-5. Am J Psychiatry 2011;168:672-4.

39. Lenzer J, Hoffman JR, Furberg CD, et al. Ensuring the integrity of clinical practice guidelines: a tool for protecting patients. BMJ 2013;347:f5535.

40. Siemieniuk RA, Agoritsas T, Macdonald H, et al. Introduction to BMJ Rapid Recommendations. BMJ 2016;354:i5191.

41. HIV and injecting drug use: a global call for action. Lancet 2011;377:1212.

42. Gandey A. US slams Canada over Vancouver's new drug injection site. CMAJ 2003;169:1063.

43. Hyman SE. The neurobiology of addiction: implications for voluntary control of behavior. Am J Bioeth 2007;7:8-11.

44. Disease PJM. diagnosis or syndrome? Pract Neurol 2011;11:91-7.

45. Scadding JG. Essentialism and nominalism in medicine: logic of diagnosis in disease terminology. Lancet 1996;348:594-6.

46. King M, Bartlett A. British psychiatry and homosexuality. Br J Psychiatry 1999;175:106-13. 